\title{
Deformation of EPS Foam Under Combined Compression- Shear Loading: Experimental and Computational Analysis
}

\author{
Chen Ling ${ }^{1, *}$, Jan Ivens $^{2}$, Philip Cardiff ${ }^{1}$, Michael D. Gilchrist ${ }^{1}$ \\ ${ }^{1}$ School of Mechanical \& Materials Engineering, University College Dublin, Dublin, Ireland \\ ${ }^{2}$ Department of Materials Engineering, KU Leuven, J. De Nayerlaan 5, B-2860 Sint-Katelijne-Waver, Belgium
}

\begin{abstract}
Expanded Polystyrene (EPS) foam material is widely used as an energy absorption engineering material. Its compression behaviour, both quasi-statically and dynamically, has been studied widely. However, its mechanical behaviour under combined compression-shear loading is poorly understood due to the difficulty of performing such tests. A novel test rig is presented to perform combined compression-shear loading tests in quasi-static loading conditions. Different densities of EPS foam were tested with this apparatus using a universal Instron testing machine. The compressive and shear stresses were obtained and compared, the results show that the shear stress at yield of EPS foam under combined compression-shear loading is much lower compared with the compressive stress at yield. On the other side, the compressive stress at yield can as high as $40 \%$ lower compared with pure compression. The FEA simulations were performed using the Abaqus/explicit 6.14 code and it is found the numerical predictions and experimental results agree closely, which indicates that our FE models exhibit good reliability in predicting the response of EPS foam under such loading conditions.
\end{abstract}

\section{Introduction}

Expanded Polystyrene (EPS) foam is a cellular material widely used for energy absorption and thermal insulation applications, such as packaging [1-2], as a structural core material [3-4], and as helmet liners [5-7]. Due to its light weight, low cost, easy manufacturability and good energy absorption, it has long been used as an engineering material in diverse applications. Modern cycling and sports helmets have been made using EPS foam as energy absorption liners for decades. Much work has been done to investigate the mechanical behaviour of EPS foam material. Its compression behaviour, both at static and dynamic strain rates, has been studied widely [8-9], but less so under the action of tensile, shear or more complex loading situations, such as compression/tension combined with shear behaviour. However, under many applications, the EPS foam is not subjected to pure compression. Most real loading cases involve the deformation of EPS foam due to a combination of compression and shear. Thus, it is very important to investigate the mechanical behaviour of EPS foam material under combined compression-shear loading conditions in order to better characterize and obtain its mechanical performance for corresponding applications.

There is extensive literature on the mechanical behaviour of EPS foam. Ashby et al. [10] studied the structure and mechanical properties of EPS as a subset of cellular solids and found that the mechanical properties (elastic, plastic, creep and fracture) of foam are related to the cell wall material properties and geometry. Chen et al. [11] further studied the effect of cell size and wall thickness variations on the stiffness of closed-cell foams, and found that the Young's modulus and shear modulus decrease with increasing cell size and cell wall thickness; expressions incorporating cell size and cell wall thickness variations were formulated to predict the stiffness of closed-cell foams. Mihlayanlar et al. [12] studied the effect of production process parameters and density of EPS on its mechanical properties and thermal conductivity and found that the foam density seems to be the dominant controlling variable regards to the mechanical property of EPS foam. The effect of production process parameters on the properties did not exceed $10 \%$, according to their study. Song et al. [13] investigated the strain-rate effects of EPS from 0.001 to $950 / \mathrm{s}$ by using a hydraulically driven test machine and modified SHPB dynamic testing system: the collapse stress and elastic modulus were found to increase with strain rate, and a rate-dependent material model was proposed to describe the experimental results. Ouellet et al. [14] studied the compressive response of EPS at quasi-static, medium and high strain rate conditions and found that the rate

Corresponding author: chen.ling@ucdconnect.ie 
effects become more pronounced at rates above approximately 1000/s. Koohbor et al. [18] investigated the dynamic stress-strain response of rigid closed-cell polymeric foams by quantifying their deformation response with high speed stereophotography and 3D digital image correlation.

As a typical foam material, the crushable foam model in Abaqus [1, 16-19] and low-density foam material model (MAT 57) in LS-Dyna $[20,21]$ are used most commonly to simulate the behaviour of EPS foam in FEA. Ozturk et al. [1] used both Abaqus and LS-Dyna to simulate the compressive behaviour and cushioning diagrams of EPS foam under multiple loadings, and found that both software codes managed to accurately predict the maximum deceleration, force, and displacement for first loading, but less so for unloading and reloading. Gilchrist et al. [16] used Abaqus to model the impact response of low-density EPS foam and accurately predicted the deformation fields of EPS foam with high-speed videos in the absence of damage, although the predictions were poor when a crack appeared in the experiments. Cui et al. [18] and Forero Rueda et al. [19] used the crushable foam model in Abaqus to consider the concepts of using either layered foam or functionally graded foam, as possible energy absorbing EPS liners for equestrian helmets.

\section{Experimental setup}

The fixture shown in Figure 1 was designed to apply compression-shear loading at a $45^{\circ}$ loading angle.

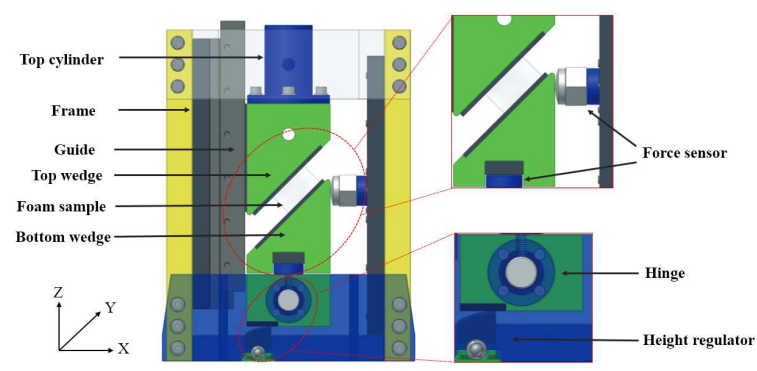

Fig. 1. The fixture designed for combined compressionshear loading on EPS foam at $45^{\circ}$ loading angle.

In this fixture, the combined compression and shear loading condition was realized by introducing two inclined $45^{\circ}$ wedges to hold the sample: the top loading wedge was restrained to Z-axis translation only, while the bottom wedge was hinged to the bottom frame, thereby allowing rotation about the Yaxis only. However, a force sensor connected to a hemispherical contact surface cylinder was set at the right side of the bottom wedge to prevent any free rotation of the bottom wedge. Simultaneously, the corresponding horizontal force was measured by the force sensor. The components of the frame are made from stainless steel and aluminium and are fixed together by bolts to increase the stiffness and robustness of the system. The top wedge, fixed with a vertical guide on the left side allowing only motion in the Z-direction, is used to apply the loading. The vertical guide is fixed on the left side of the frame with screws, ensuring that all other motions of the top wedge block are prevented. A cylinder with a flat top surface is connected to the top wedge to apply the load or displacement, for instance by the crosshead of the Instron machine, thus applying a load or displacement control to the EPS foam sample. A height regulator is set under the left bottom side of the fixed block, making it possible to regulate the location of the block subtly, thereby ensuring good contact between the bottom wedge and horizontal force sensor at the beginning of the test.

Two force sensors are used to measure the forces during the loading: A Kistler 1-component force sensor (Type 9041A), mounted inside the bottom wedge, is used to measure the vertical force during the test. As the bottom wedge has the freedom to rotate around the Y-axis once the vertical load is applied, and as this rotation is constrained by a similar Kistler force sensor, which is fixed horizontally to the right side of the frame and hemispherical point contact with the right side of the bottom wedge, this means that a horizontal reaction force is created and measured by this force sensor during the test. The contact area is specially designed, as shown in Figure 1, in the form of a hemispherical shape to ensure that only horizontal force is transmitted to the Kistler load cell. The vertical loading is transmitted to the EPS foam through the guide by the crosshead of the Instron machine. As the guide is practically frictionless, the friction loss results from the guide during the tests can be ignored; this was verified separately by comparing the vertical load value from the Kistler load cell and the Instron load cell: only an insignificant difference was found. The compressive and shear forces on the foam samples can then be obtained based on the horizontal and vertical forces measured from the Kistler force sensors.

Fig. 2 shows the scheme of the force measurement fixture, depending on the test wedge angle, the shear and compression forces are obtained directly via:

$$
\begin{aligned}
& F_{S}=F_{V} \sin \theta-F_{H} \cos \theta, \\
& F_{C}=F_{H} \sin \theta+F_{V} \cos \theta,
\end{aligned}
$$

where $F_{S}$ and $F_{C}$ are the shear and compression forces on the foam material and $F_{V}$ and $F_{H}$ are the vertical and horizontal forces recorded by the Kistler force sensors. $\theta$ is the angle between the vertical direction and the normal direction of the contact surface. 


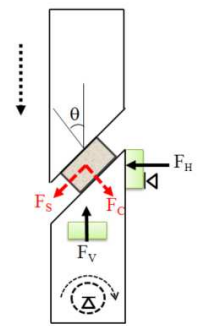

Fig. 2. The force measurement fixture includes a frictionless hinge joint on the bottom platen.

\section{Quasi-static tests results}

The test rig was fixed under the crosshead of the Instron machine, a compression mode with a quasistatic loading speed of $10 \mathrm{~mm} / \mathrm{min}$ was used. The LIMESS strain field measuring system was set up to focus on the deformation of the foam. Due to the slow deformation of the foam material under quasistatic loading, a low sampling rate was adopted, in which the camera was programmed to take one picture every two seconds.

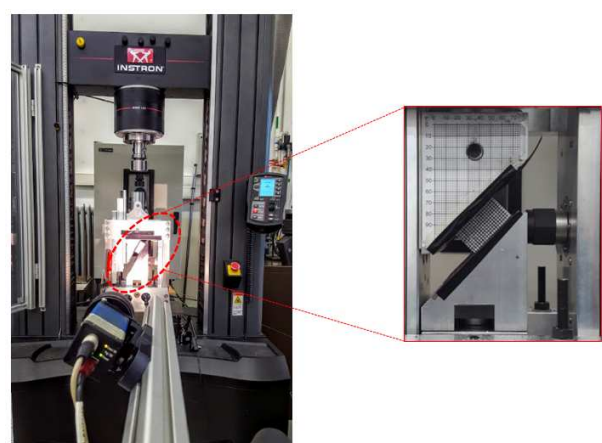

Fig. 3. Experimental setup with Instron machine and LIMESS system.

The stress and strain curves for different density foam samples are presented below in Fig. 4.

The shear stress at yield is much lower than the compressive stress at yield for the same density foam, as listed in Table 1 below, though both of them increase directly with foam density.

Table 1. Comparison of compressive and shear stress at yield for different densities foam.

\begin{tabular}{ccccc}
\hline Foam density $\left(\mathrm{kg} / \mathrm{m}^{3}\right)$ & 43 & 64 & 80 & 120 \\
\hline $\begin{array}{c}\text { Compressive stress at yield } \\
(\mathrm{MPa})\end{array}$ & 0.22 & 0.32 & 0.47 & 0.92 \\
\hline Shear stress at yield $(\mathrm{MPa})$ & 0.10 & 0.13 & 0.16 & 0.27 \\
\hline
\end{tabular}

Table 2 compares the compressive stress at yield of the foam using the $45^{\circ}$ compression wedge and pure compression respectively. As can be seen, the stress at yield under the $45^{\circ}$ compression wedge is lower when compared with that for pure compression.
Table 2. Comparison of compressive stress at yield for different densities foam under $45^{\circ}$ compression wedge and pure compression.

\begin{tabular}{ccccc}
\hline $\begin{array}{c}\text { Foam density } \\
\left(\mathrm{kg} / \mathrm{m}^{3}\right)\end{array}$ & 43 & 64 & 80 & 120 \\
\hline $\begin{array}{c}\text { Compressive stress at yield } \\
\text { under } 45^{\circ} \text { compression } \\
\text { wedge loading } \\
(\mathrm{MPa})\end{array}$ & 0.22 & 0.32 & 0.47 & 0.92 \\
\hline $\begin{array}{c}\text { Compressive stress at yield } \\
\text { under pure compression } \\
(\mathrm{MPa})\end{array}$ & 0.33 & 0.53 & 0.70 & 1.26 \\
\hline
\end{tabular}

(a)

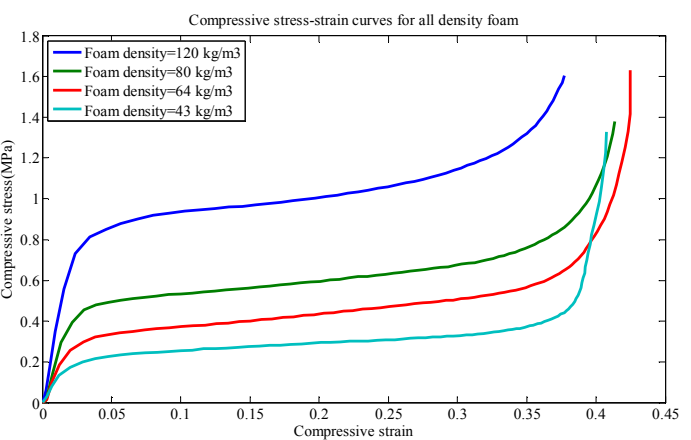

(b)

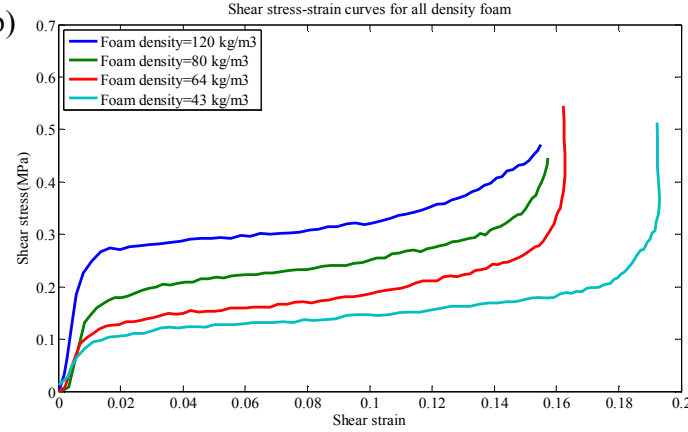

Fig. 4. (a) compressive stress strain curve; (b) shear stress strain curve of EPS foam under quasi-static loading at $45^{\circ}$ loading angle.

\section{FEA simulations}

FEA simulations were performed using the Abaqus/Explicit 6.14 code to simulate the deformation response of EPS foam under quasi-static combined compression-shear loading, the compressive and shear forces obtained from the simulations are then validated against with the experimental results.

Figure 6 compares the compressive and shear forces of EPS foam under quasi-static loading as measured experimentally and predicted numerically. The numerical predictions for yielding agree closely with experiments for both compressive and shear forces, and for all the foam densities. 


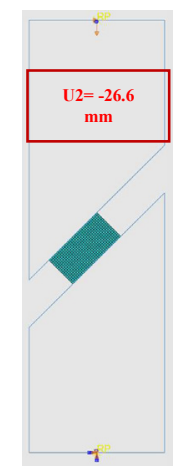

Fig. 5. The loading condition for the quasi-static simulation $(\mathrm{U} 2=-26.6 \mathrm{~mm})$.

(a)

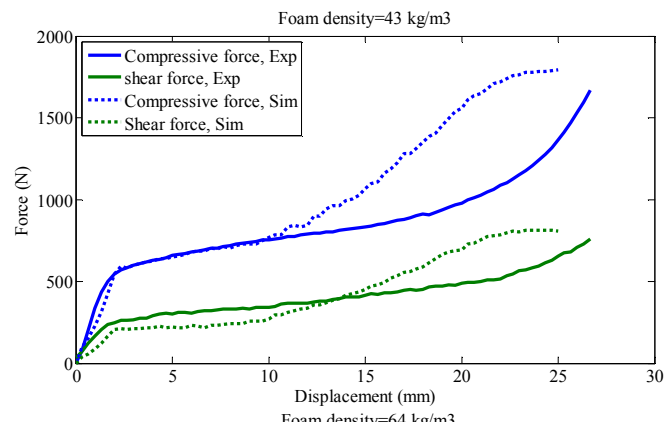

(b)

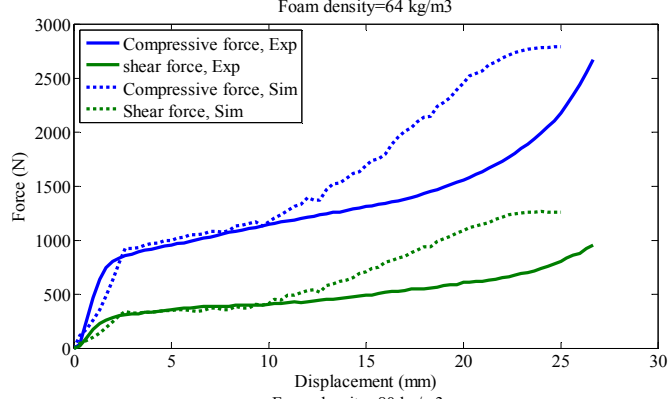

(c)

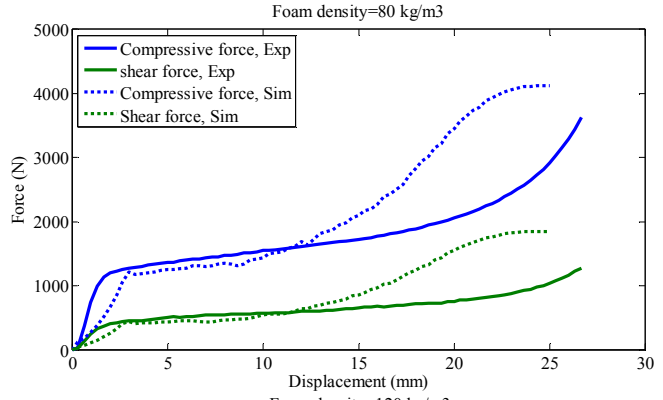

(d)

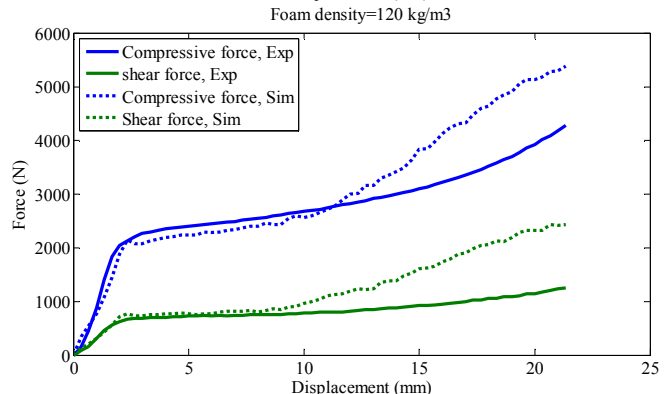

Fig. 6. Comparison of the compressive and shear forces of different density EPS foam under quasi-static loading between experiments and simulations: (a) Foam density $=43 \mathrm{~kg} / \mathrm{m}^{3}$; (b) Foam density $=64 \mathrm{~kg} / \mathrm{m}^{3}$; (c) Foam density $=80 \mathrm{~kg} / \mathrm{m}^{3}$; (d) Foam density $=120 \mathrm{~kg} / \mathrm{m}^{3}$. (Note Xaxis is the displacement of loading wedge in vertical direction).
Table 3 compares the measured and predicted deformations of $64 \mathrm{~kg} / \mathrm{m}^{3}$ EPS foam. It is seen that, at $80 \mathrm{~s}$ in the simulation (which corresponds to 13.3 $\mathrm{mm}$ displacement of the loading wedge), the left side of the foam contacts the bottom wedge ${ }^{1}$, which is consistent with the increasing change rates of compressive and shear force curves from simulations in Fig. 6. Overall, Table 3 shows that the predicted deformations of the EPS foam are very similar to those observed experimentally, both in terms of the change of foam thickness and general deformation. However, the early contact between the left side of the foam and the wedge suggests that a more comprehensive material model and more accurate material parameters need to be developed and used if all aspects of the mechanical behaviour of the foam under combined compression and shear loading are to be predicted with complete accuracy.

\section{Conclusions}

This paper presents the experimental study and FEA investigation of the deformation response of EPS foam under quasi-static combined compression-shear loading. The main conclusions that can be drawn from this study are:

- The shear stress at yield of EPS foam is lower when compared with the compressive stress at yield under quasi-static combined compression-shear loading,

- The shear deformation tends to weaken the compressive stress at yield of the EPS foam compared with which under pure compression. This difference was found to be as much as $40 \%$, depending on the density of the foam sample,

- The numerical model exhibits a good agreement with the experimental results, in terms of the Young's modulus and magnitude of the forces at yield.

This work was sponsored by the European Union's Horizon 2020 programme under Marie Skłodowska-Curie grant agreement (No. 642662). The authors thank technicians Marc Peeters and Joop van Deursen from KU Leuven for the design, manufacture of the test rig and discussion of the experimental results.

\footnotetext{
${ }^{1}$ The initial contact moment between the left side of the foam and the bottom wedge actually happens earlier than $80 \mathrm{~s}$ loading time in the simulation, as Table 3 only shows several discrete loading times captured from the simulations.
} 
Table 3. Comparison of the physical and predicted deformation process of $64 \mathrm{~kg} / \mathrm{m}^{3}$ EPS foam.

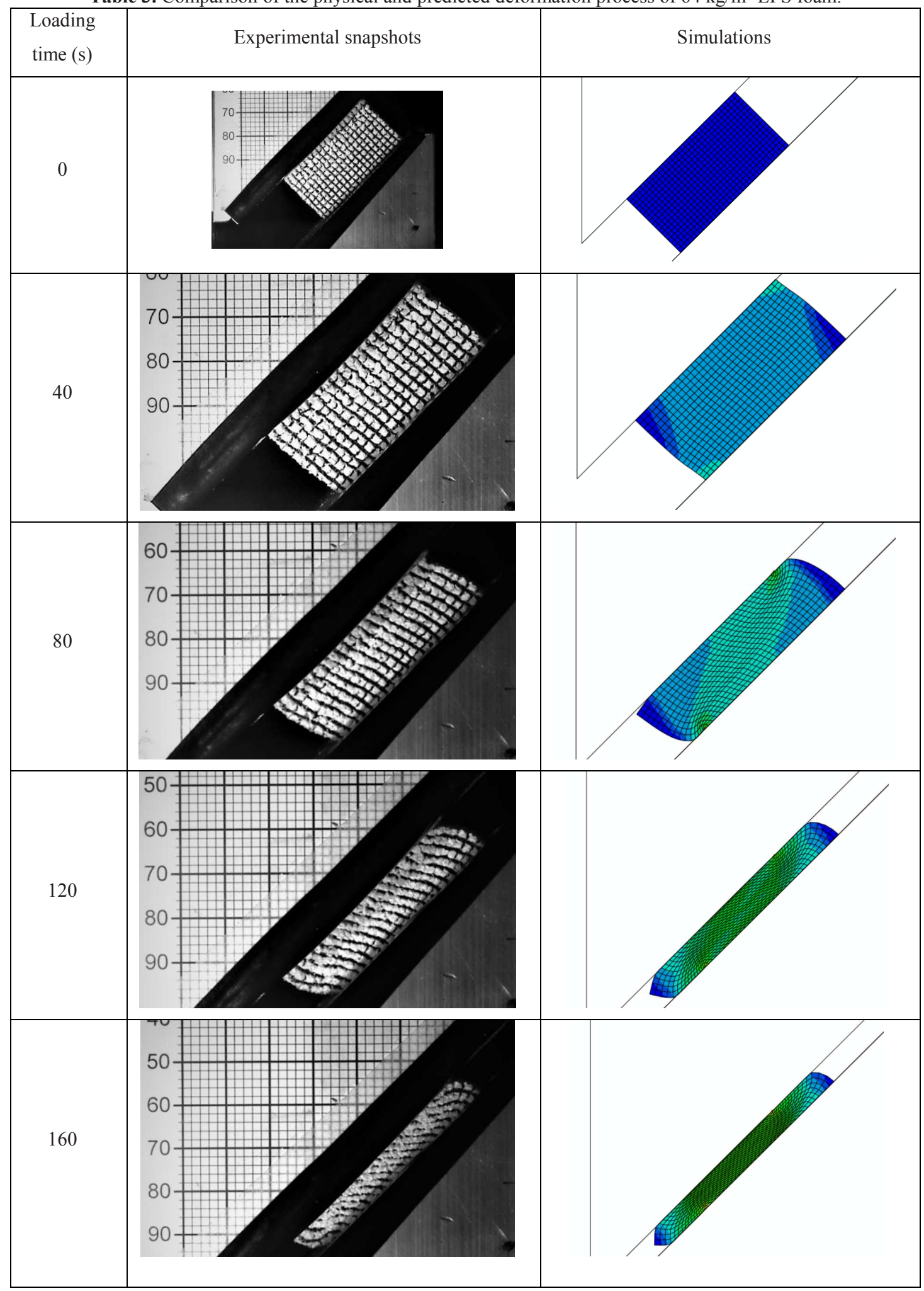

\section{References}

1. U.E. Ozturk and G. Anlas, Finite element analysis of expanded polystyrene foam under multiple compressive loading and unloading. Materials \& Design,. 32(2): p. 773-780 (2011)
2. S.P. Singh, G. Burgess, and J. Singh, Performance comparison of thermal insulated packaging boxes, bags and refrigerants for single-parcel shipments. Packaging Technology and Science, 21(1): p. 25-35 (2008)

3. P.L.N. Fernando, M.T.R. Jayasinghe, and C. Jayasinghe, Structural feasibility of Expanded 
Polystyrene (EPS) based lightweight concrete sandwich wall panels. Construction and Building Materials, 139: p. 45-51 (2017)

4. D.S. Babu, K.G. Babu, and T.H. Wee, Properties of lightweight expanded polystyrene aggregate concretes containing fly ash. Cement and Concrete Research, 35(6): p. 1218-1223 (2005)

5. L. Di Landro, G. Sala, and D. Olivieri, Deformation mechanisms and energy absorption of polystyrene foams for protective helmets. Polymer Testing, 21(2): p. 217-228 (2002)

6. L. Cui, L., R. Forero, and M.D. Gilchrist, Optimisation of energy absorbing liner for equestrian helmets. Part II: Functionally graded foam liner. Materials \& Design, 30(9): p. 3414-3419 (2009)

7. R. Forero, L. Cui, and M.D. Gilchrist, Optimisation of energy absorbing liner for equestrian helmets. Part I: Layered foam liner. Materials \& Design, 30(9): p. 3405-3413 (2009)

8. W. Chen et al., Static and dynamic mechanical properties of expanded polystyrene. Materials \& Design, 69: p. 170-180 (2015)

9. A. Krundaeva et al., Dynamic compressive strength and crushing properties of expanded polystyrene foam for different strain rates and different temperatures. Polymer Testing, 55: p. 61-68 (2016)

10. M.F. Ashby, The Mechanical-Properties of Cellular Solids. Metallurgical Transactions aPhysical Metallurgy and Materials Science, 14(9): p. 1755-1769 (1983)

11. Y.M. Chen, R. Das, and M. Battley, Effects of cell size and cell wall thickness variations on the stiffness of closed-cell foams. International Journal of Solids and Structures, 52: p. 150-164 (2015)

12. E. Mihlayanlar, S. Dilmac, and A. Guner, Analysis of the effect of production process parameters and density of expanded polystyrene insulation boards on mechanical properties and thermal conductivity. Materials \& Design, 29(2): p. 344-352 (2008)

13. B. Song et al., Strain-rate effects on elastic and early cell-collapse responses of a polystyrene foam. International Journal of Impact Engineering, 31(5): p. 509-521 (2005)

14. S. Ouellet, D. Cronin, and M. Worswick, Compressive response of polymeric foams under quasi-static, medium and high strain rate conditions. Polymer Testing, 25(6): p. 731-743 (2006)

15. B. Koohbor et al., Investigation of the dynamic stress-strain response of compressible polymeric foam using a non-parametric analysis. International Journal of Impact Engineering, 91: p. 170-182 (2016)

16. A. Gilchrist and N.J. Mills, Impact deformation of rigid polymeric foams: experiments and FEA modelling. International Journal of Impact Engineering, 25(8): p. 767-786 (2001)

17. L. Cui, S. Kiernan, and M.D. Gilchrist, Designing the energy absorption capacity of functionally graded foam materials. Materials Science and Engineering a-Structural Materials Properties Microstructure and Processing, 507(1-2): p. 215-225 (2009)

18. L. Cui, M.A.F. Rueda, and M.D. Gilchrist, Optimisation of energy absorbing liner for equestrian helmets. Part II: Functionally graded foam liner. Materials \& Design, 30(9): p. 3414-3419 (2009)

19. M.A.F. Rueda,.L. Cui, and M.D. Gilchrist, Optimisation of energy absorbing liner for equestrian helmets. Part I: Layered foam liner. Materials \& Design, 30(9): p. 3405-3413 (2009)

20. LS-DYNA Theory Manual. Livermore Software Technology

21. H.L. B. Croop, Selecting material models for the simulation of foams in LSDYNA, in: 7th European LS-DYNA Conference (2009) 